\title{
Fabrication of Low-cost Artificial Tibia Bone Using Polyurethane Rigid Foam and Epoxy Resin for Orthopedic Surgical Skills Training
}

\author{
Coral Pink R. Bagares, MD, ${ }^{1,2}$ Gracia Cielo E. Balce, MD ${ }^{1}$ and Juanito S. Javier, MD, MCh.Orth. ${ }^{1}$ \\ ${ }^{1}$ Department of Orthopedics, Philippine General Hospital, University of the Philippines Manila, Manila \\ ${ }^{2}$ Department of Orthopedics and Traumatology, Vicente Sotto Memorial Medical Center, Cebu City, Cebu
}

\begin{abstract}
Introduction. Skills training using artificial bones became more critical in response to the Orthopedic surgical training restriction caused by the COVID-19 pandemic. To cut the expenses of buying commercial artificial bones, the llizarov Limb Reconstruction Service has decided to fabricate its artificial bones for surgical skills training.

Objective. To determine if resin-coated polyurethane (PU) rigid foam is a suitable, low-cost alternative to commercial artificial bone.

Methods. Tibiae were fabricated using PU rigid foam coated with epoxy resins. Three randomly selected fabricated tibia, and one standard artificial tibia was subjected to drilling with drill bits and K-wires. The time to penetration of one cortex of the three segments of the tibiae was recorded in seconds. An actual circular external fixator was applied. The actual cost of production was calculated.
\end{abstract}

Results. Each fabricated tibia costs $¥ 456.93$. The fabricated tibiae mean time to penetration was $2.15 \mathrm{~s}$ and $3.37 \mathrm{~s}$ using drill bits and K-wires. The commercial artificial bone mean time to penetration was $3.41 \mathrm{~s}$ and $3.57 \mathrm{~s}$ with drill bits and K-wires. The fabricated tibia was able to withstand the application of a circular external fixator and corticotomy.

Conclusion. The fabricated tibia is a suitable and more affordable simulation model for surgical skills training.

Keywords: education, surgical procedures, artificial bone

Corresponding author: Coral Pink R. Bagares, MD Department of Orthopedics Philippine General Hospital University of the Philippines Manila

Taft Avenue, Ermita, Manila 1000, Philippines

Email: crbagares@up.edu.ph

\section{INTRODUCTION}

On the $30^{\text {th }}$ of January 2020, the World Health Organization (WHO) declared that the SARS-CoV-2 outbreak constituted a Public Health Emergency of International Concern. ${ }^{1}$ By $11^{\text {th }}$ of March 2020, the WHO has declared the novel coronavirus (COVID-19) outbreak a global pandemic. ${ }^{1}$

Because of the social distancing policies and the overall decreased number of Orthopedic surgeries, alternative technical educational tools were sought worldwide. $^{2}$ Technologies surrounding surgical simulation were being advanced and validated, and access to cadaver and synthetic bone simulations has increased. ${ }^{2}$ Orthopedic training courses delivered by the British Orthopaedic Association and The Royal College of Surgeons laid out learning outcomes to include employment of technology-enhanced learning (TEL) and simulation to educate trainees remotely. ${ }^{3}$ Locally, in our setting, orthopedic surgical skills training has been significantly affected; hence the Ilizarov Limb 
Reconstruction Service resorted to making its artificial bones for simulation purposes.

Cadaveric bones have been used for an extended period for research and educational purposes. Such bones were used for biomechanical studies on fracture fixation construct and orthopedic implants and an accurate anatomy model for academic and surgical skills development. ${ }^{4}$ Being a valuable model for technical skills development, cadaveric bones are widely used in Orthopedics, including training in external fixation or applying Ilizarov frames. The disadvantages of cadaveric bones include high cost, logistics, storage and preserving methods, and procurement due to ethical, religious, and cultural controversies. ${ }^{4,5}$

The development of a synthetic bone that recreates the biomechanical properties of the human bone was due to the challenges encountered with the use of cadaveric specimens. ${ }^{4}$ Composite bone models are available in different formulations to achieve the desirable properties needed for several Orthopedic procedures or resemble a particular Orthopedic condition. ${ }^{6}$ The available fourth-generation composite bones are made of solid rigid polyurethane foam as a cancellous core. A mixture of fiberglass and epoxy resin is injected around the foam to mimic the cortical bone. ${ }^{7}$ Though it addresses the disadvantages of using cadaveric bones, synthetic bones are still costly. The price of artificial tibia bones designed for use with implants ranges from $\$ 42.25$ ( $(\mathbf{P} 2,036.00)$ to $\$ 76.50$ ( $(\mathrm{P} 3,687.00)$, depending on the materials used and the biomechanical properties. ${ }^{6}$

\section{Relevance of the Study}

The Ilizarov Limb Reconstruction Service of the Department of Orthopedics has been offering artificial bone workshops annually for 21 years. Such skills training workshops are among those affected by social distancing to prevent the spread of the COVID-19 virus. In response to the global lockdown, several measures must be carried out to adapt, such as utilizing the online platform and seeking alternative methods to teach Orthopedic surgical skills.

In the local setting, there was an urgent need to produce cheap simulations during the pandemic to continue the skills training of Orthopedic residents amidst the low surgical cases brought about by the lockdown. This study involved the fabrication of artificial tibia bones from readily available and cheap materials. The goal was to simulate the feel of going through the cortices when drilling or fixing bones. While a biomechanically realistic model would have been more optimal, the investigators did not have access to a biomechanical tester during the time. If the present composition of these artificial tibiae is good enough for fixation and reconstruction simulations, the exact proportions may be used to fabricate other body bones for simulation purposes.

\section{Objectives}

This is a descriptive study with the primary objective to fabricate an artificial tibia bone composed of resin- coated PU rigid foam suitable as a simulation model for Orthopedic surgical skills training.

Specifically, the study aims:

1. To calculate the total cost of production of a resin-coated PU rigid foam tibia.

2. To determine the mean time to penetration the first cortex of the resin-coated PU rigid foam tibia compared to the commercially available artificial bones.

3. To determine if resin-coated PU rigid foam tibia can withstand the entire application process of an Ilizarov frame.

\section{MATERIALS AND METHODS}

The fabrication of the artificial tibia bone and the data collection and analysis was carried out at the Department of Orthopedics - Spine Building. The study was conducted from October 2020 to January 2021.

\section{Production of $\mathrm{PU}$ rigid foam tibia}

An artificial tibia bone was fabricated using materials sourced locally through actual physical and online stores. Two negative molds were made from a commercially available synthetic bone obtained from one of the past local AO workshops. The model mentioned above was also used as the standard for this study. Room temperature vulcanizing (RTV) silicone was used for the molds and the base of the molds from Epoxy Marine (Figure 1A). The artificial tibia bone was cast into the silicone mold using $30 \mathrm{~mL}$ part A and $30 \mathrm{~mL}$ part $\mathrm{B}$ of $\mathrm{PU}$ rigid foam. Before pouring the PU mixture into the mold, a Mould Release was sprayed to prevent the casted PU from sticking to the silicone mold. Quick grip C-clamps were used to hold the mold together (Figure 1B). The PU foam casting was then removed from the mold after 40 minutes (Figure 1C), and surfaces were cleaned and smoothened using grit-220 sandpaper (Figure 2A).

After cleaning the surfaces, an equal amount of Multipurpose Epoxy Resin and its hardener were mixed, then applied to the surface of the PU foam casting using a wooden craft stick (Figure 3) and allowed to cure for 24 hours per product instruction. A second layer of the Multipurpose Epoxy Resin was applied and allowed to cure again for another 24 hours (Figure 2B). Once dried, the surfaces were smoothened using grit-220 sandpaper. A final layer of Epoxy Structural Adhesive, by mixing equal amounts of the resin and hardener, was applied just enough to cover the surface or at approximately $1 \mathrm{~mm}$ in thickness (Figure 4A) using a clean 1-inch scraper (Figure $4 \mathrm{~B}$ ) then allowed to cure for at least 9 hours per product instruction. The rough surfaces were cleared using grit-80 sander followed by grit220 sander to smoothen (Figure 5 and Figure 2C). This was then cleaned and sprayed with plastic primer and, after 10 minutes, sprayed matte white paint. This was dried for at least 25 minutes, then finally coating with an off-white Acrylic spray paint (Figure 2D). 

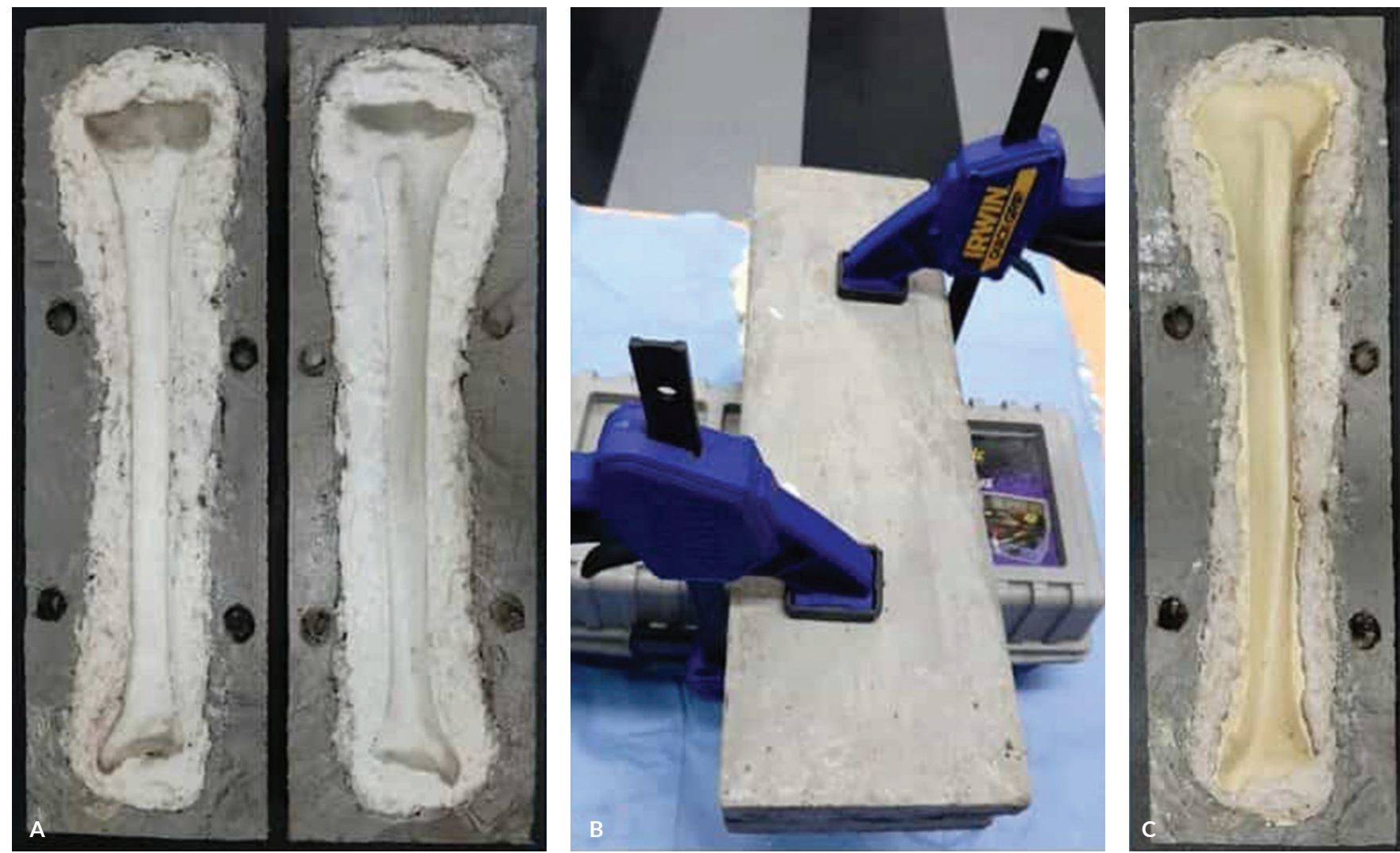

Figure 1. Negative molds were made using room temperature vulcanizing (RTV) silicone with Epoxy Marine as its base (A). Quick grip C-clamps were used to hold the mold together (B). Casted PU foam tibia as it is removed from the mold (C).

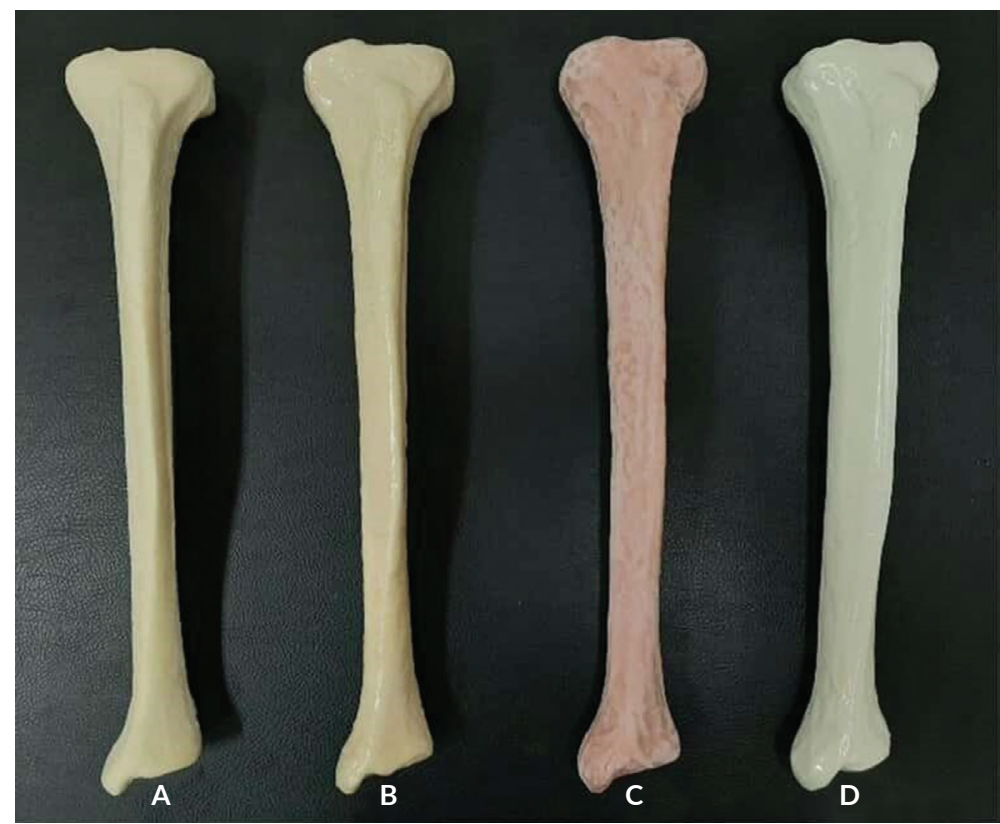

Figure 2. The casted PU foam tibia after edges were cleaned and surfaces smoothened using grit-220 sandpaper (A). After application of the second layer of Multipurpose Epoxy Resin (B). Epoxy Structural Adhesive layer after sanding with grit-220 (C). Final product after coating with off-white Acrylic spray paint (D).

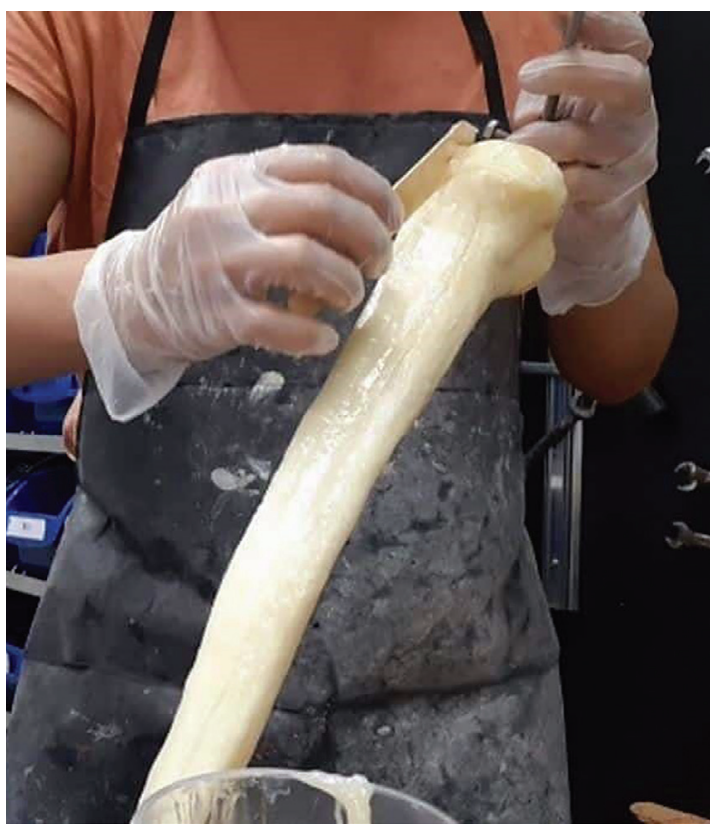

Figure 3. Application of Multipurpose Epoxy Resin unto the surface of the casted PU foam tibia using a wooden craft stick. 

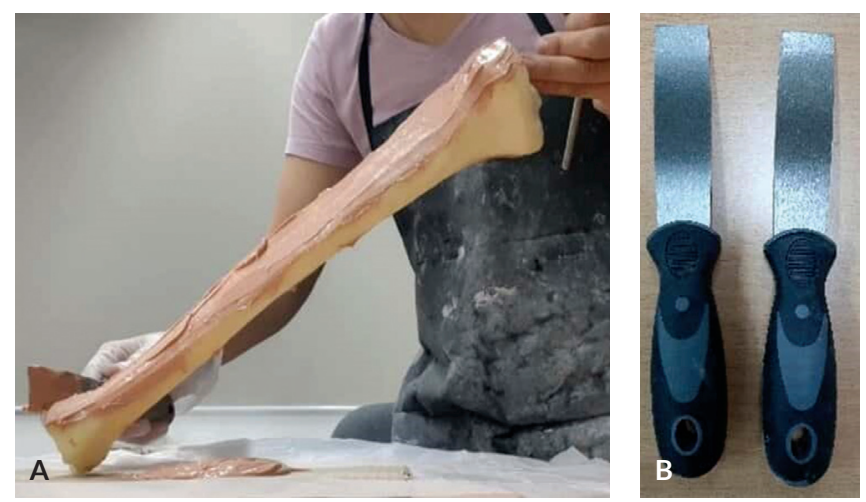

Figure 4. Application of Epoxy Structural Adhesive just enough to cover the surface or approximately $1 \mathrm{~mm}$ thick (A) using a clean 1-inch scraper (B).

\section{Drilling of the artificial bones}

One skilled surgeon from the Department of Orthopedics did the drilling of all artificial bones to minimize any discrepancy in the skills level. The time to penetration refers to the time it takes for a Kirschner-wire or a drill bit, attached to a drill, to perforate one cortex of a bone. This will simulate the feel and the time it takes to drill an actual bone cortex. The surgeon drilled the epiphyseal and proximal and distal metaphyseal area of the resin-coated PU rigid foam tibia using a new $4.0 \mathrm{~mm}$ surgical drill bit intended for implant preparation and a $2.0 \mathrm{~mm}$ stainless steel Kirschner-wire. This was performed in 3 randomly selected, resin-coated PU rigid foam that was cast. The time to penetration, in seconds, of one cortex of the fabricated artificial bones was recorded. A similar procedure was done to one standard artificial tibia, and the time to penetration was recorded.

\section{Application of the llizarov frame on resin-coated PU rigid foam tibia}

A 4-ring construct of the Ilizarov frame was applied to one randomly selected, resin-coated PU rigid foam tibia. Two $2.0 \mathrm{~mm} \mathrm{~K}$-wires and one $6.3 \mathrm{~mm}$ half-pin were used on each level. Middle tibia corticotomy was performed using multiple drill holes and osteotomy technique. This part of the study checked if the fabricated resin-coated PU rigid foam tibia can withstand the entire process of the Ilizarov fixation procedure. One randomly selected resin-coated PU rigid foam tibia was cut in half in the coronal plane to determine the thickness of the resin coatings. One standard artificial tibia was also cut into half in the coronal plane for comparison.

\section{Data Collection}

The primary author collected data. The sale price of each material and equipment was collected and used to compute the actual cost of fabricating one artificial tibia bone. A timeline in making one artificial tibia bone was compiled to determine the total amount of production time. The time to penetration of one cortex using a drill bit and

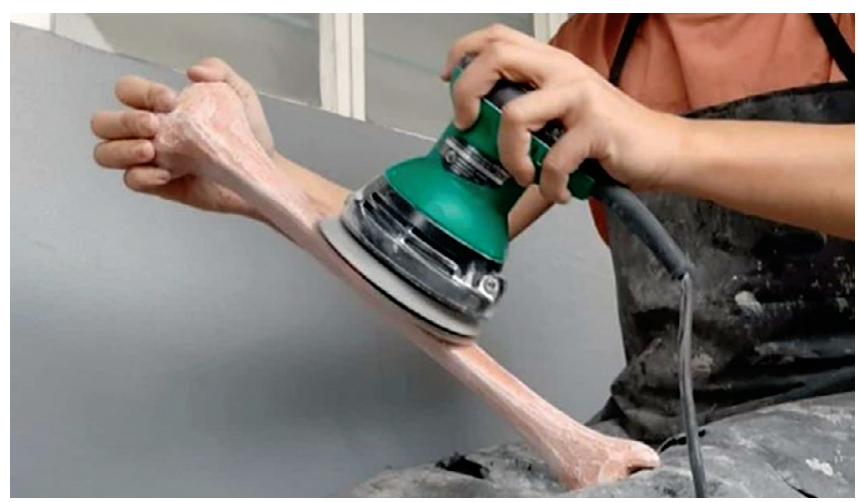

Figure 5. An orbital sander was used to clear the rough surface using grit-80 sandpaper followed by grit-220 sandpaper to smoothen.

$\mathrm{K}$-wire was recorded per area (diaphysis and proximal and distal metaphyses).

\section{Data Analysis}

The total amount of fabricating one resin-coated PU tibia bone was calculated based on all materials and equipment used and was compared to the actual sale price of a standard artificial tibia. The mean time to penetration of one cortex of the fabricated tibia bone was computed and compared to penetration of one cortex of a single standard artificial tibia.

\section{RESULTS}

The authors were able to fabricate artificial tibiae made of materials procured locally and from online stores. Each fabricated tibia costs P248.11, whereas each mold costs $\mathrm{P} 4,500.00$ to make. Equipment and other materials used in the fabrication process costs $\mathrm{P} 7,705.00$ in total (Appendix). Since the process would require a long curing time for the resins, 24 hrs for each layer of the multipurpose epoxy resin, and nine hours for the epoxy structural adhesive, the minimum amount of time to fabricate one tibia was three days. The authors were able to fabricate ten tibiae simultaneously in three days.

The overall mean time to penetration of the fabricated tibia was $2.15 \mathrm{~s}$ using a $4.0 \mathrm{~mm}$ drill bit and $3.37 \mathrm{~s}$ using a $2.0 \mathrm{~mm} \mathrm{~K}$-wire. For the standard tibia, the mean time to penetration was $3.41 \mathrm{~s}$ with a $4.0 \mathrm{~mm}$ drill bit and $3.57 \mathrm{~s}$ with a $2.0 \mathrm{~mm} \mathrm{~K}$-wire. The mean time to penetration of each segment of the fabricated tibia, the proximal, middle, and distal thirds, were $2.65 \mathrm{~s}, 2.28 \mathrm{~s}$, and $1.52 \mathrm{~s}$, using the $4.0 \mathrm{~mm}$ drill bit and $4.27 \mathrm{~s}, 3.97 \mathrm{~s}$, and $1.86 \mathrm{~s}$, respectively using the $2.0 \mathrm{~mm} \mathrm{~K}$-wire. The standard tibia time to penetration on each segment was $2.23 \mathrm{~s}, 6.29 \mathrm{~s}$, and $1.71 \mathrm{~s}$, using the $4.0 \mathrm{~mm}$ drill bit and $2.89 \mathrm{~s}, 6.12 \mathrm{~s}$, and $1.71 \mathrm{~s}$, respectively, using the $2.0 \mathrm{~mm} \mathrm{~K}$-wire (Table 1).

The fabricated tibia was able to withstand the entire process of application of an actual 4-ring construct Ilizarov 
Table 1. Comparison of the cost of production and mean time to penetration

\begin{tabular}{|c|c|c|c|c|c|c|c|c|c|}
\hline \multirow{2}{*}{\multicolumn{2}{|c|}{ Artificial Tibia Cost (P) }} & \multicolumn{8}{|c|}{ Time to penetration (seconds) } \\
\hline & & \multicolumn{4}{|c|}{ Drill Bit } & \multicolumn{4}{|c|}{ K-Wire } \\
\hline & & $\mathrm{P} / 3$ & $M / 3$ & $\mathrm{D} / 3$ & Mean & $\mathrm{P} / 3$ & $M / 3$ & $D / 3$ & Mean \\
\hline Fabricated & 456.93 & 2.65 & 2.28 & 1.52 & 2.15 & 4.27 & 3.97 & 1.86 & 3.37 \\
\hline Standard & $2,861.50$ & 2.23 & 6.29 & 1.71 & 3.41 & 2.89 & 6.12 & 1.71 & 3.57 \\
\hline
\end{tabular}

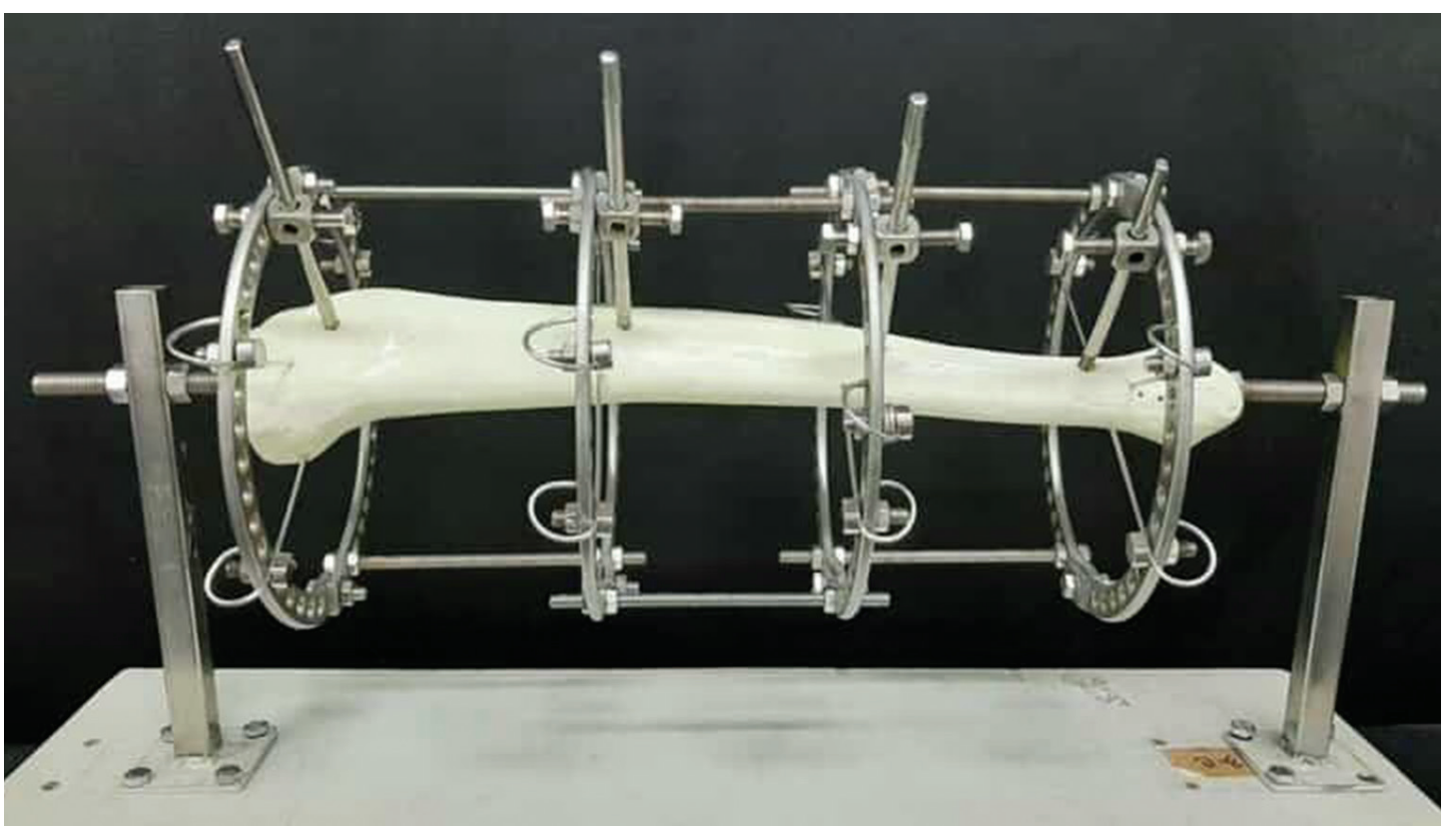

Figure 6. Application of a 4-ring construct Ilizarov frame on fabricated, resin-coated PU tibia.

frame and the middle tibia corticotomy (Figure 6). On the coronal section, the thickness of the epoxy resin and structural adhesive, which acted as the cortices, were 1-2 $\mathrm{mm}, 1.5-2.5 \mathrm{~mm}$, and 1-2 $\mathrm{mm}$ from proximal, middle, and distal sections, respectively (Figure 7A). For the standard artificial tibia, the thickness of the cortices was $5 \mathrm{~mm}, 4 \mathrm{~mm}$, and $4.5 \mathrm{~mm}$ from proximal, middle, and distal segments, respectively (Figure $7 \mathrm{~B}$ ).

\section{DISCUSSION}

The cost of the mold for each casted tibia was $\mathrm{P} 112.50$, the price for the materials used to fabricate one tibia was P248.11, and the cost of the equipment and other materials used in the fabrication process was P96.32 per tibia (Appendices 1 and 2). Thus, the total cost of fabricating one tibia using locally available materials was P456.93 (Table 1). This cost was six times lower than the standard commercial artificial bones, costing around $\mathrm{P} 2,861.50$ ( $\mathrm{P} 2,036.00$ P3,687.00) each. ${ }^{6}$ The computation was done at the cutoff point of 40 tibiae per mold; though the molds are still useable, and the equipment was only purchased once and used again, the cost is expected to further down. Since ten tibiae can be fabricated simultaneously in 3 days, given its low cost and readily available materials, any training institution can have these produced anytime they want for an educational simulation model for use by surgeons in training.

The mean time to penetration one cortex was longer by $1.26 \mathrm{~s}$ and $0.2 \mathrm{~s}$ with the standard artificial tibia using the drill bit and $\mathrm{K}$-wires, respectively. However, comparing the time to penetration of the three segments of the tibia showed that the penetration was longer on the middle segment of the standard artificial tibia by $4.01 \mathrm{~s}$ and $2.15 \mathrm{~s}$, both with the drill bit and $\mathrm{K}$-wire. These differences in the penetration of the middle segment, which was comparable to an actual bone observed during surgery, are because commercial artificial bones of any brand were designed to recreate the biomechanical properties of the human bone. ${ }^{6}$ This was not followed in our fabricated tibiae since the resin coatings, which acted as the cortices, were spread equally throughout the casted PU tibia's surface and were thinner than the cortices of the cortices standard artificial tibia (Figure 7). Fabrication of a biomechanically equivalent tibia was also not an objective of this study. In general, the time to penetration for the rest of the tibia segments was comparable using the drill bit and $\mathrm{K}$-wire for both fabricated and standard artificial tibia. The fabricated tibiae provided the feel of having a cortex, which is also essential in skills training. However, the 

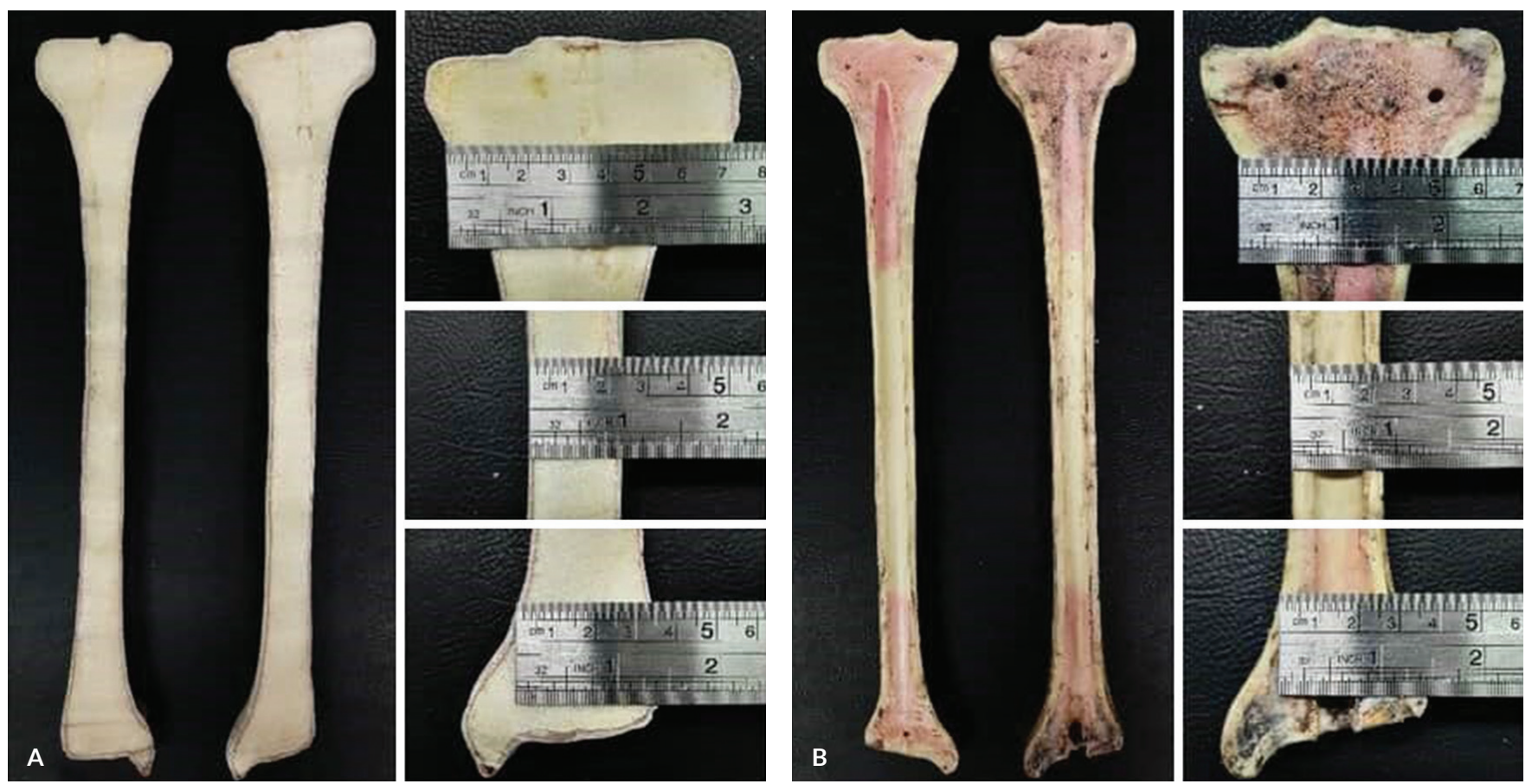

Figure 7. Coronal cut of fabricated, resin-coated PU tibia (A) in comparison with a standard commercial artificial tibia (B).

significant difference of the time to penetration between the fabricated tibiae and standard artificial tibia cannot be tested robustly due to the small sample size.

The fabricated tibia was also able to withstand the entire process of application of an actual 4-ring construct Ilizarov frame (Figure 6). The feel and give of drilling the cortices were handled both with the drill bit and $\mathrm{K}$-wires throughout the process. The toughness of the cortices was also adequate to have a good purchase with $6.3 \mathrm{~mm}$ half-pins. For the corticotomy part, multiple drilling had similar qualities as mentioned; however, it was noted to propagate during osteotomy quickly.

\section{CONCLUSION}

In conclusion, the fabricated, resin-coated PU tibia can serve as an alternative and suitable simulation model for Orthopedic surgical skills training. Its low-cost production and immediate availability of the materials that were used make it a good option, replacing commercial artificial bones that are not only expensive but have to be ordered overseas.

\section{Recommendation}

It is recommended that future studies increase the sample size and test multiple standard bones to verify the difference in the penetration time. The sample size of this study was limited by the funds available of the service at the time of conduct of the study. The study was not aiming for a biomechanically accurate model at the time as we did not have access to a biomechanical tester. Further research is recommended to test the biomechanical properties of these fabricated tibiae. The quality and ease of production can still be improved.

\section{Acknowledgment}

The authors thank the Ilizarov and Limb Deformity Service, Department of Orthopedics, Philippine General Hospital for their financial support of this study.

\section{Statement of Authorship}

Dr. Bagares, conducted the study and responsible for the acquisition and analysis of data for the work; Drafting the work; Approved the final version to be published; Shares accountability for all aspects of the work in ensuring that questions related to the accuracy or integrity of any part of the work are appropriately investigated and resolved.

Dr. Balce and Dr. Javier, conceptualized the work; Revising the work critically for important intellectual content; Approved the final version to be published; Shares accountability for all aspects of the work in ensuring that questions related to the accuracy or integrity of any part of the work are appropriately investigated and resolved.

\section{Author Disclosure}

The authors declared no conflicts of interest. This article does not contain any studies with human or animal subjects performed by any of the authors.

\section{Funding Source}

This study was funded by the Ilizarov and Limb Deformity Service, Department of Orthopedics, Philippine General Hospital. 


\section{REFERENCES}

1. Cucinotta D, Vanelli M. WHO Declares COVID-19 a Pandemic. Acta Biomed. 2020 Mar; 91(1):157-60.

2. Stambough JB, Curtin BM, Gililland JM, Guild GN 3rd, Kain MS, Karas V, et al. The Past, Present, Future of Orthopedic Education: Lessons Learned from the COVID-19 Pandemic. J Arthroplasty. 2020 Jul; 35(7):S60-S64.

3. Khajuria A, Mathew Jr J. Simulation Training and Skills Assessment in Orthopedic Surgery. In: StatPearls [Internet]. Treasure Island (FL): StatPearls Publishing; Updated 2020 Sept [cited 2020 Nov]. Available from: https://www.ncbi.nlm.nih.gov/books/NBK559080/.
4. Elfar J, Menorca RM, Reed JD, Stanbury S. Composite Bone Models in Orthopaedic Surgery Research and Education. J Am Acad Orthop Surg. 2014 Feb; 22(2):111-20.

5. Thiel W. The Preservation of the Whole Corpse with Natural Color Ann Anat. 1992 Jun; 174(3):185-95.

6. Sawbones, Product Catalogue [Internet]. 2020 [cited 2020 Nov]. Available from: https://www.sawbones.com/catalog/orthopaedicmodels.html?cat $=12$.

7. Shim V, Boheme J, Josten C, Anderson I. Use of Polyurethane Foam in Orthopaedic Biomechanical Experimentation and Simulation. In: Zafar F, Sharmin E. Polyurethane. IntechOpen; 2012.

\section{APPENDICES}

Appendix 1. Sale Price of Materials for Fabrication

\begin{tabular}{|c|c|c|c|c|}
\hline & Date Purchased & Sale Price (P) & Number of tibiae & Price per tibia $(\mathbb{P})$ \\
\hline \multicolumn{5}{|l|}{ Materials for Fabrication } \\
\hline Polyurethane rigid foam, 1-pint set & Oct 2020 & 700.00 & 6 & 116.67 \\
\hline Aeropak mould release spray, 1 can & Oct 2020 & 250.00 & 29 & 8.62 \\
\hline V-tech multipurpose epoxy, 0.5 pint & Oct 2020 & 419.00 & 9 & 46.56 \\
\hline Pioneer epoxy structural adhesive, 0.5 pint & Nov 2020 & 189.00 & 9 & 21.00 \\
\hline Bosny spray paint plastic primer, 1 can & Nov 2020 & 400.00 & 33 & 12.12 \\
\hline Pylox lazer spray matte white, 1 can & Nov 2020 & 382.00 & 17 & 22.47 \\
\hline Bosny spray paint vespa white, 1 can & Nov 2020 & 88.00 & 12 & 7.33 \\
\hline Sandpaper Grit 80, 1 pc & Oct 2020 & 20.00 & 3 & 6.67 \\
\hline Sandpaper Grit 220, 1 pc & Oct 2020 & 20.00 & 3 & 6.67 \\
\hline Sub Total & & & & 248.11 \\
\hline \multicolumn{5}{|l|}{ Materials for the Molds } \\
\hline Epoxy Marine, $5 \mathrm{~L}$ & Oct 2020 & $3,600.00$ & 80 & 45.00 \\
\hline RTV Silicone Rubber, $4 \mathrm{~L}$ & Oct 2020 & 675.00 & 80 & 67.50 \\
\hline Sub Total & & & & 112.50 \\
\hline Total & & & & 360.61 \\
\hline
\end{tabular}

Appendix 2. Sale Price of Equipment and other Materials Used to Fabricate 80 Tibiae

\begin{tabular}{lcrr}
\hline & Date Purchased & Sale Price (P) & Price per Tibia (P) \\
\hline Equipment and Other Materials & & \\
1-inch Scraper, 2 pcs & Nov 2020 & 100.00 & 1.25 \\
Disposable Plastic Cups 25s, 5 pcs & Oct 2020 & 175.00 & 2.19 \\
Steel Brush, 1 pc & Nov 2020 & 90.00 & 1.13 \\
Irwin Quick Grip C-Clamps 6", 2 pc & Oct 2020 & $2,580.00$ & 32.25 \\
Single Use Powder Free Gloves, 4 boxes & Oct 2020 & $1,560.00$ & 19.50 \\
Brush 1", 2 pcs & Oct 2020 & 80.00 & 1.00 \\
Plastic Measuring Cups, 4 pcs & Nov 2020 & 80.00 & 1.00 \\
Wooden Craft Stick 50s, 4 pcs & Nov 2020 & 100.00 & 1.25 \\
Makita Orbit Sander & Dec 2020 & $2,940.00$ & 36.75 \\
\hline Total & & & 96.32 \\
\hline
\end{tabular}

